\title{
Effects of Orexin A on Thermal Behaviour: Substantial Evidences for Thermoregulatory Role of Orexin A
}

\author{
Emanuela Viggiano', Giovanni Messina' ${ }^{1}$, Andrea Viggiano ${ }^{2}$, Alessandro Viggiano', Vincenzo De Luca ${ }^{3}$, Antonietta Messina ${ }^{1}$ and Marcellino
} Monda $^{1 *}$

${ }^{1}$ Department of Experimental Medicine-Section of Human Physiology, Second University of Naples, Naples, Italy

${ }^{2}$ Department of Medicine and Surgery, University of Salerno, Salerno, Italy

${ }^{3}$ Department of Psychiatry, University of Toronto, Toronto, Canada

\begin{abstract}
Orexin $A$ is a hypothalamic neuropeptide produced in the dorsal and lateral hypothalamus, and orexin-producing cell have widespread anatomical projections within the central nervous system. Orexin $A$ is involved in multiple physiological functions, including eating behavior, thermoregulation, and sleep-regulation. The aim of this work was to study the thermal preference induced by orexin $\mathrm{A}$. A thermal preference task with floor thermal gradient from $16^{\circ} \mathrm{C}$ to $25^{\circ} \mathrm{C}$, divided into 10 equal segments, was designed to evaluate the thermal preferences in rats. Male rats $(n=10$, divided into two groups of five animals) received an intracerebroventricular injection of $1.5 \mathrm{nmol}$ of orexin $A$ or vehicle and were subsequently tested for thermal preference for $4 \mathrm{~h}$. The results showed that the rats injected with orexin $\mathrm{A}$ had increased motor activity compared to the control group, particularly after the second hour of the test. Moreover the group treated with orexin A preferred hotter temperatures ranging from 24 to $25^{\circ} \mathrm{C}$ compared to the control group that preferred temperature of $22^{\circ} \mathrm{C}$, which is near room temperature for rat housing $\left(22 \pm 1^{\circ} \mathrm{C}\right)$. No significant correlation was seen between thermal preference and time (hours). Since orexin A induces thermal preference, this study indicates that this neuropeptide plays a key role in the thermoregulation.
\end{abstract}

Keywords: orexin A; motor activity; thermal preference

\section{Introduction}

Orexin A is a hypothalamic neuropeptide whose name was formerly introduced because of its putative role in eating behavior $[1,2]$. Actually, studies on orexin A have demonstrated its role in the regulation of different physiological functions-such as blood pressure [3], metabolic rate [2], body temperature [4], awakening [5,6], heart rate [7]-suggesting, overall, a role of orexin $\mathrm{A}$ in the control of vegetative functions. Moreover, orexin $\mathrm{A}$ has an important role in thermoregulation; in fact, an Intra Cerebro Ventricular (ICV) injection of orexin A can increase body thermal. This effect is present both in anesthetized rats and in animals without access to food, and suggests that thermogenesis induced by orexin is not only a consequence of food intake or motor activity [8,9]. It has been hypothesized that orexin A modulates body thermal through the medial preoptic area $[10,11]$-a region involved in central thermoregulation - and numerous orexin projections are present in this area [12]. In addition, the inhibitors of the synthesis of prostaglandins, which act on this region, block the hyperthermia induced by orexin $\mathrm{A}$ in anesthetized rats [13]. Alternatively, orexin A could modulate thermogenesis directly through activation of the autonomic system; in fact, an ICV injection of orexin A increases the sympathetic output to inter scapular brown adipose tissue (IBAT) [14], which is the major source of non shivering-termogenesis and energy balance $[15,16]$. Several studies on the interaction between antipsychotic drugs and the orexin system showed that the thermogenic effect of orexin A also involve serotoninergic and dopaminergic systems. The increase in the sympathetic activity induced by orexin A is reduced by antipsychotic drugs, such as haloperidol, that are antagonist of $\mathrm{D}_{2}$ receptors $[7,17]$. Furthermore atypical antipsychotic drugs, such as olanzapine, that are $5-\mathrm{HT}_{2}$ receptor and $\mathrm{D}_{2}$ receptor antagonists $[18,19]$, decrease or block hyperthermic effects of orexin A [20]. Because thermoregulation depends on both vegetative and behavioral mechanisms, the aim of the present study was to evaluate the thermal behaviour induced by orexin A, namely, whether an ICV injection of orexin A can modify the thermal preference in rats. To this end, a cage with a gradient thermal along the floor and a transparent wall was used to record, through a computerized visual system, the overall time spent moving or resting at each thermal ranging from 16 to $25^{\circ} \mathrm{C}$.

\section{Methods}

\section{Animals}

Male Sprague Dawley rats $(\mathrm{n}=10$, divided randomly into two groups of five animals) weighing between 250 and 300 g (age: 9-10 weeks) were used for the experiments. The rats were housed in pairs at controlled thermal $\left(22 \pm 1^{\circ} \mathrm{C}\right)$ and humidity $(70 \%)$ with a $12: 12 \mathrm{~h}$ lightdark cycle with light from 07:00 to 19:00, and with access to food and water ab libitum. The experiments were conducted in accordance with the European Communities Council Directive of 24 November 1986 (86/609/EEC) and were approved by Animal Research Committee.

\section{Surgery}

All animals were anesthetized with intra-peritoneal injection of chloral hydrate $(0.6 \mathrm{~g} / \mathrm{kg})$. A stainless guide cannula $(0.9 \mathrm{~mm}$ in diameter) was stereotaxically placed above a lateral cerebral ventricle at the following coordinates: $1.7 \mathrm{~mm}$ lateral to the midline, $0.4 \mathrm{~mm}$ posterior to the bregma, $3.0 \mathrm{~mm}$ from the cranial theca [21]. The rats

*Corresponding author: Marcellino Monda, Department of Experimental Medicine, Section of Human Physiology, Second University of Naples, via S.M. di Costantinopoli, 16, 80138 Naples, Italy, Tel: +390815665804; E-mail: marcellino.monda@unina2.it

Received August 13, 2014; Accepted October 28, 2014; Published November 03, 2014

Citation: Viggiano E, Messina G, Viggiano A, Viggiano A, Luca VD, et al (2014) Effects of Orexin A on Thermal Behaviour: Substantial Evidences for Thermoregulatory Role of Orexin A. J Bioanal Biomed 6: 040-044. doi:10.4172/1948$593 \times .1000108$

Copyright: ( 2014 Viggiano E, et al. This is an open-access article distributed under the terms of the Creative Commons Attribution License, which permits unrestricted use, distribution, and reproduction in any medium, provided the original author and source are credited. 
were given 7-10 days to recover from surgery before the experiments.

\section{Orexin A injection}

A dose of $1.5 \mathrm{nmol}$ of orexin A (Sigma-Aldrich, Italy), dissolved in $5 \mathrm{~mL}$ of $0.9 \% \mathrm{NaCl}$ sterile solution, was used for the ICV injection. Previous experiments showed that this is a submaximal dose for the induction of hyperthermia [22]. Orexin A (or saline) was injected unilaterally into the left cerebral ventricle by gravity flow $(1 \mathrm{~min})$ over $2 \mathrm{~min}$. The injected volume was controlled using a transparent polyethylene tube with a graduation of microliters. The cannula $(0.8 \mathrm{~mm}$ in diameter) used for the injection was $0.4 \mathrm{~mm}$ longer than the guide cannula. The flow of the fluid, controlled by gravity, confirmed the correct position of the cannula into the lateral cerebral ventricle.

\section{Thermal preference task}

The thermal preference was evaluated with a custom cage that consisted of a rectangular copper floor of $150 \mathrm{~cm} \times 15 \mathrm{~cm}$ and four walls $(30 \mathrm{~cm}$ in height). Three of the walls were constructed with blackpainted wood, and a transparent Plexiglas wall was used for one of the longer sides of the cage. Underneath the copper floor, two adjacent copper tubes produced a thermal gradient due to heat exchange between cold water flowing in one tube and hot water flowing in the other one. The flow rate and the prime thermals of the water were adjusted to have a thermal gradient on the floor of the cage between $16^{\circ} \mathrm{C}$ at one extremity and $25^{\circ} \mathrm{C}$ at the other extremity (Figure 1 ).

\section{Procedure}

After recovery, the experiments were conducted during the light phase to minimize the effect of the endogenous orexin A that is high during the dark phase [23]. Orexin A (or saline) was injected into the left cerebral ventricle by gravity over $2 \mathrm{~min}$. The injected animal was then placed in the thermal-preference apparatus for $4 \mathrm{~h}$. The position of the animal along the long axes of the cage was automatically determined and recorded continuously by a computerized visual system that consisted of a simple web-cam framing the cage through the transparent wall and attached to a PC. Custom software written with Lab View (National Instruments, Texas, USA) recognized the animal due to the high contrast between his white coat and the black background (Figure 1). The cage was divided into ten segments and the time spent resting on each segment was calculated. Resting was defined as staying in the same segment for at least one minute. The time spent moving was also calculated.

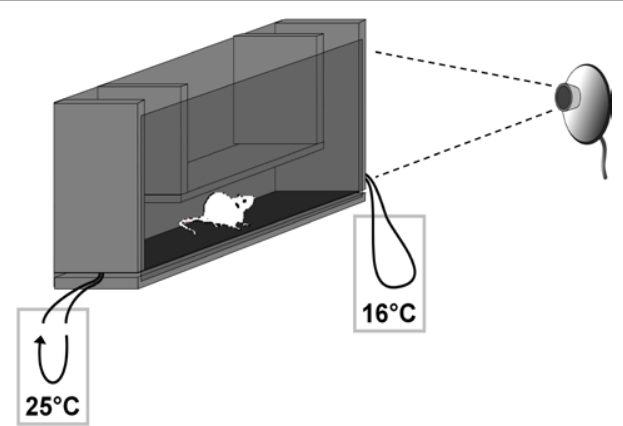

Figure 1: Schematic of the apparatus for the evaluation of thermal preference. The cage consisted of a rectangular copper floor with two adjacent copper tubes that produced a thermal gradient due to heat exchange between cold water flowing in one tube and hot water flowing in the other one. The cage was divided into ten segments with a $1^{\circ} \mathrm{C}$ difference between one other. The thermal gradient ranged from $16^{\circ} \mathrm{C}$ at one extremity to $25^{\circ} \mathrm{C}$ at the other extremity.

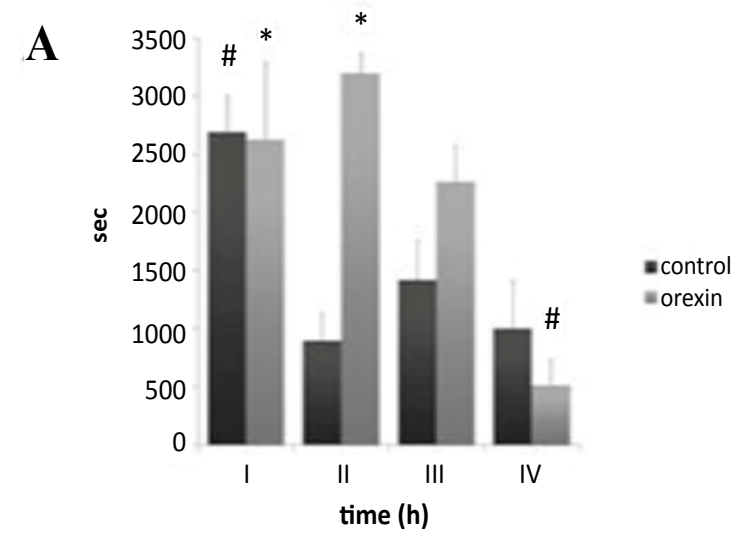

Figure 2a: Total moving time spent by the animals at 1, 2, 3 and 4 hours after ICV injection of vehicle (dark gray) or orexin A (light gray). The control animals showed high locomotor activity in the first hour, whereas rats treated with orexin A showed high locomotor activity in the first two hours compared to the fourth hour and in the second hour compared to the other time. The locomotor activity of the orexin A group is high in the first and second hour compared to the control group at 2, 3 and 4 hours.

\section{Statistical analysis}

Data are presented as mean \pm standard error of mean. Statistical analysis was performed using the Analysis Of Variance (ANOVA). Multiple comparisons were performed using the Fisher-LSD post hoc test. Parameters were analyzed using SPSS 10.0 for Windows (SPSS Inc., Chicago, IL). A P value of less than 0.05 was considered significant.

\section{Results}

\section{Orexin A injection caused a significant increase in the time spent moving}

The ANOVA for the time spent moving showed a significant difference for the following factors: treatment (orexin $A$, saline) $[\mathrm{F}(1,40)=6.474 ; \mathrm{P}<0.05]$, time $(1,2,3,4$ hour $)[\mathrm{F}(3,40)=9.667 ; \mathrm{P}<0.01]$, and the interaction term treatment ${ }^{\star}$ time $[\mathrm{F}(3,40)=5.878 ; \mathrm{P}<0.01]$. The LSD Fisher post hoc test showed a significant difference for the time spent moving between the following: $1 \mathrm{~h}$ and the other hours in the control group $(\mathrm{P}<0.05) ; 4 \mathrm{~h}$ and the other hours in the orexin A group $(\mathrm{P}<0.01)$; orexin $\mathrm{A}$ at $1-2 \mathrm{~h}$ and control group at 2,3 and $4 \mathrm{~h}(\mathrm{P}<0.01)$. The total time spent moving by the control group was higher in the first hour compared to the other hours. The total time spent moving by the orexin A group was higher in the first two hours compared to the control group (Figure 2A). Moreover, the total time spent moving of the orexin A group was significantly higher $(43.2 \pm 13.1 \%)$ than the control group.

\section{Orexin A injection caused a significant shift of the thermal preference toward higher thermals}

The ANOVA for the time spent resting at each temperature showed a significant difference for the following factors: temperature $[\mathrm{F}(9,400)=3.295 ; \mathrm{P}<0.01]$, the interaction treatment ${ }^{*}$ temperature $[\mathrm{F}(9,400)=3.438 ; \mathrm{P}<0.01]$ and the interaction temperature ${ }^{\star}$ time $[\mathrm{F}(27,400)=2.035 ; \mathrm{P}<0.01]$. No significant difference was showed for the following factors: treatment $[\mathrm{F}(1,400)=0.979 ; \mathrm{P}=0.323]$, time $[\mathrm{F}(3,400)=2.574 ; \quad \mathrm{P}=0.054]$, interaction treatment ${ }^{*}$ time $[\mathrm{F}(3,400)=2.529 ; \mathrm{P}=0.057]$, the interaction treatment ${ }^{\star}$ temperature ${ }^{\star}$ time $[F(27,400)=0.936 ; P=0.56]$. The LSD Fisher post hoc test showed a 
significant difference between the orexin A group and the control group for the time resting at $25-24(\mathrm{P}<0.05)$ and $22^{\circ} \mathrm{C}(\mathrm{P}<0.01)$. The orexin A group spent significantly more time at $24-25^{\circ} \mathrm{C}$ compared to the control group, while the control group spent significantly more time at $22^{\circ} \mathrm{C}$ compared to the orexin group (Figure 2B).

\section{Discussion}

The present study demonstrates that the ICV injection of orexin A causes an increase in locomotor activity and a modification of the thermal preference in rats. Both rats treated with the saline (control) and orexin A showed higher locomotor activity in the first hour as compared with the other hours. This result suggests simply a response to the novel environment. In fact, the rats explore for a time period ranging between 30 and $90 \mathrm{~min}$ with phases of progression and stopping if placed in a new environment. Subsequently, they stop in one preferred place-called 'home place'-for very long periods [24,25]. The orexin A group also showed an increase in motor activity during the second hour compared to the third and fourth hour, and compared to the control group at 2, 3 and $4 \mathrm{~h}$. This result suggests that orexin A immediately increases locomotor activity, and that this effect is longlasting. This data agrees with previous studies that show that ICV injection of orexin increases motor activity- in particular, spontaneous motor activity, locomotor activity and the grooming until $90 \mathrm{~min}$ [26]. Also, orexin A presents a decrease in motor activity during the dark phases, when motor activity is normally increased compared to the light phase $[27,28]$.

The present study also showed that non-treated animals preferred temperatures of $22^{\circ} \mathrm{C}$, which is near room temperature for rat housing $\left(22 \pm 1^{\circ} \mathrm{C}\right)$, while the orexin A group preferred temperatures of 24 $25^{\circ} \mathrm{C}$. This preference did not depend by the time. This result suggests an effect of orexin A on thermal behavior. Thermal preference depends on body temperature, sleep-wakefulness, locomotor activity, and whether they are housed alone or within groups. In particular, rats have exhibited decreased body temperature, motor activity, wakefulness with increased frequency of sleep episodes, and prefer higher temperatures during the light (non-activity) phase. During the

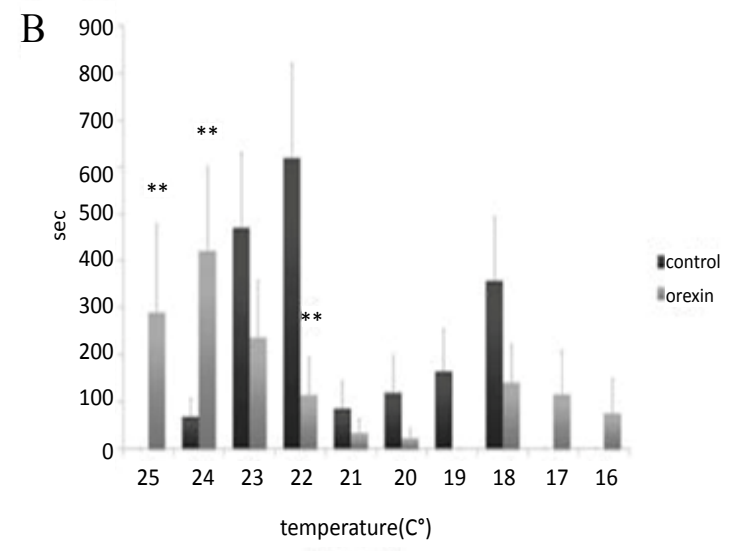

Figure 2b: Resting time spent by the animals for each segment of the thermal preference apparatus in the first (A), second (B), third (C) and fourth (D) hour after ICV injection of vehicle (dark gray) or orexin $A$ (light gray). The orexin A group spent more time at $24-25^{\circ} \mathrm{C}$ compared to the control group. The values are expressed as mean percentage $\pm S E M$. Asterisk indicates a significant difference $(P<0.05)$.

\# compared to the other hours; * compared to the control group at 2, 3 and 4 hours; ${ }^{* *}$ compared to the control group dark (activity) phase, they have exhibited increased body temperature, motor activity, and wakefulness, and prefer lower temperatures [29]. Using an environmental chamber with three interconnected compartments at 24,27 or $30^{\circ} \mathrm{C}$, respectively, some studies reported that rats preferred an ambient temperature of $24^{\circ} \mathrm{C}$ at night and $27^{\circ} \mathrm{C}$ during the day [29-31]. Also, the maximum REM sleep time was calculated at $29-30^{\circ} \mathrm{C}$ [29-31]. Another study demonstrated that rats preferred to stay at the $24^{\circ} \mathrm{C}$ chamber for most of the time during both day and night [32]. In both cases the animals were housed at a controlled temperature of $25 \pm 1^{\circ} \mathrm{C}$. Moreover, the thermo neutralityor the ambient temperature in which metabolic rate is minimal, and when rats show normal activity-ranges from $18 \pm 1.9$ to $28.1 \pm 1^{\circ} \mathrm{C}$ in rats [33]. In our work we used a thermal preference task with a larger range of temperatures, and the rats were housed at a lower temperature $\left(22 \pm 1^{\circ} \mathrm{C}\right)$. Therefore, the preference for lower temperatures compared to the other studies could depend on the lower temperature at which the rats were habituated, and could also depend on the higher range of temperatures used in the thermal task. However, the orexin group showed a preference for higher temperatures compared to the control group. Therefore, we suggest that this thermal behavior is ultimately dependent on the effect of orexin A. In fact, during the dark phasewhen the rats exhibited an increase in motor activity and awake time, and preferred low temperatures [29,34]-the level of orexin A is higher than during the light phase [23]. Moreover, orexin knockout mice shows, in particular during the dark phase, less motor activity, less body temperature, and less wakefulness compared to wild type [35-37]. The reason for the higher temperature preference in the rats treated with orexin A is difficult to explain. We hypothesized that this is another mechanism of thermogenesis induced by orexin A. Orexin A ICV determines an increase in thermogenesis, and a consequent increase in body temperature through different mechanisms. These mechanisms include the following: increases of the IBAT temperature [38] through a direct innervation of the intermedio-lateral column of spinal cord by orexin-fibers [39], and an increase of sympathetic activity [40]; increase of food intake [41,42]; and increase of motor activity [26,43]. These mechanisms determined an increase of body temperature for several hours, and suggest a long-lasting effect of the orexin. Usually the thermal behavioral response to hyperthermia would be the preference to return from lower temperatures to the baseline temperature; however, in our experiments we find that rats prefer hotter temperatures after the ICV administration of orexin A. Previous studies also showed that orexin A acts on the pre optic area, and probably increase the thermostat setting. Therefore, we hypothesize that the ICV administration of orexin A increases the thermostat setting through the activation of different pathways, and increases the body temperature to match the thermostat setting. In particular orexin A, in addition to the reported mechanisms, immediately increases locomotor activity until $2 \mathrm{~h}$. After the effect on locomotor activity ends, the rats prefer hotter temperatures in order to increase their body temperature.

The present experiment is a very valid demonstration that orexin A is a thermoregulatory peptide. This idea has been already supposed by the authors of this experiment, by demonstrating a paradoxical eating behavior (hyperphagia and hypophagia) induced by orexin A. Indeed, Monda et al. [44] report an experiment where food intake and body temperature were monitored in $24 \mathrm{~h}$-fasting male Sprague-Dawley rats for $15 \mathrm{~h}$ after food presentation during the dark period. Orexin A was injected into the lateral cerebral ventricle $6 \mathrm{~h}$ before food presentation. Food intake and body temperature were controlled also in rats receiving orexin A at the same time of food presentation.

Orexin A caused the same elevation of body temperature in 
both groups, while food intake was significantly lower in the group receiving orexin A $6 \mathrm{~h}$ before food presentation in comparison to the other group. This study demonstrated that the effects on food intake induced by orexin A depend on the time of food presentation. This induces us to revise the role of orexin $\mathrm{A}$ in the control of food intake. The name assigned to this peptide was due to the strong increase in food intake after an orexin A administration, assigning a fundamental role in the induction of food intake $[45,46]$. The results of the above publication call for a re-discussion of this role, underlining the importance of orexin A in the control of the sympathetic activity and body temperature, which in turn affects food intake. An icv injection of orexin A induces an increase in the sympathetic activity and in the body temperature independently of food ingestion that is reduced in the rats with a delayed presentation of food. This suggests that the effects on body temperature are prevalent with respect to eating behavior. Then, orexin A can induce hyperphagia, but also hypophagia, contradicting the significance of this name that assign a primary hyperphagic effect to this peptide. Other substances with primary hyperphagic effect, as neuropeptide $\mathrm{Y}$ or galanin, induce a reduction of the sympathetic discharge and a decrease in body temperature [20,47-52].

Conversely, substances with a primary hypophagic effect cause an increase in the sympathetic activity. For example, leptin induces reduction of food intake [53-55], along with an increase in the firing rate of the sympathetic nerves to IBAT and a rise in $\mathrm{T}_{\text {IBAT }}[56,57]$. For this reason, orexin A cannot be considered a substance with a primary hyperphagic effect. The orexin A can induce hypophagia or hyperphagia [45], but it always induces an activation of thermogenesis. We can suppose that this peptide elevates the thermoregulatory set-point, inducing the reactions to reach the new level of body temperature. The increase in food intake, obtained in the rats with a non-delayed presentation of food, could be a reaction aimed to reach an elevated body temperature. Indeed, food ingestion induces a rise in body temperature due to post-prandial thermogenesis [58-62]. The hyperphagic effect of orexin A disappears when the body temperature is already increased, so that a reduction in food intake can happen in this condition.

Since thermoregulation is highly coordinated with sleep and cardiovascular control, further experiments could be carried out with analysis of these physiological parameters. Furthermore, additional experiment should be performed using animals lacking orexin $\mathrm{A}$ and blocking orexin A receptors.

In conclusion, the thermoregulatory role of orexin A is substantially demonstrated by the findings reported in this paper.

\section{Acknowledgment}

The authors are grateful to Dr. Adela Viggiano for technical assistance and for reviewing the manuscript.

\section{References}

1. de Lecea L, Kilduff TS, Peyron C, Gao X, Foye PE, et al. (1998) The hypocretins: hypothalamus-specific peptides with neuroexcitatory activity. Proc Natl Acad Sci U S A 95: 322-327.

2. Lubkin M, Stricker-Krongrad A (1998) Independent feeding and metabolic actions of orexins in mice. Biochem Biophys Res Commun 253: 241-245.

3. Shirasaka T, Nakazato M, Matsukura S, Takasaki M, Kannan H (1999) Sympathetic and cardiovascular actions of orexins in conscious rats. Am J Physiol 277: R1780-1785

4. Yoshimichi G, Yoshimatsu H, Masaki T, Sakata T (2001) Orexin-A regulates body temperature in coordination with arousal status. Exp Biol Med (Maywood) 226: $468-476$.
5. Beuckmann CT, Yanagisawa M (2002) Orexins: from neuropeptides to energy homeostasis and sleep/wake regulation. J Mol Med (Berl) 80: 329-342.

6. Thannickal TC, Moore RY, Nienhuis R, Ramanathan L, Gulyani S, et al. (2000) Reduced number of hypocretin neurons in human narcolepsy. Neuron 27: 469474

7. Monda M, Viggiano A, De Luca V (2003) Haloperidol reduces the sympathetic and thermogenic activation induced by orexin A. Neurosci Res 45: 17-23.

8. Bray GA (2000) Reciprocal relation of food intake and sympathetic activity: experimental observations and clinical implications. Int J Obes Relat Metab Disord 24 Suppl 2: S8-17.

9. Monda M, Viggiano AN, Viggiano AL, Fuccio F, De Luca V (2004) Cortica spreading depression blocks the hyperthermic reaction induced by orexin $A$. Neuroscience 123: 567-574.

10. Monda M,Amaro S, Sullo A, De Luca B (1995) Injection of muscimol in the posterior hypothalamus reduces the PGE1-hyperthermia in the rat. Brain Res Bull 37: 575-580.

11. Stitt JT (1986) Prostaglandin E as the neural mediator of the febrile response. Yale J Biol Med 59: 137-149.

12. Peyron C, Tighe DK, van den Pol AN, de Lecea L, Heller HC, et al. (1998) Neurons containing hypocretin (orexin) project to multiple neuronal systems. $J$ Neurosci 18: 9996-10015.

13. Monda M, Sullo A, De Luca E, Pellicano MP (1996) Lysine acetylsalicylate modifies aphagia and thermogenic changes induced by lateral hypothalamic lesion. Am J Physiol 271: R1638-1642.

14. Monda M, Viggiano AN, Viggiano A, Viggiano E, Lanza A, et al. (2005) Hyperthermic reactions induced by orexin $A$ : role of the ventromedial hypothalamus. Eur J Neurosci 22: 1169-1175.

15. Foster DO (1984) Quantitative contribution of brown adipose tissue thermogenesis to overall metabolism. Can J Biochem Cell Biol 62: 618-622.

16. Himms-Hagen J (1984) Nonshivering thermogenesis. Brain Res Bull 12: 151 160

17. Damase-Michel C,Montastruc JL, Gharib C, Geelen G, De Saint-Blanquat G et al. (1990) Effect of quinpirole, a specific dopamine DA2 receptor agonist on the sympathoadrenal system in dogs. J Pharmacol Exp Ther 252: 770-777.

18. Grant S, Fitton A (1994) Risperidone. A review of its pharmacology and therapeutic potential in the treatment of schizophrenia. Drugs 48: 253-273.

19. Nemeroff CB, Kinkead B, Goldstein J (2002) Quetiapine: preclinical studies, pharmacokinetics, drug interactions, and dosing. J Clin Psychiatry 63 Supp 13: 5-11.

20. Monda M, Viggiano A, Viggiano A, Mondola R, Viggiano E, et al. (2008) Olanzapine blocks the sympathetic and hyperthermic reactions due to cerebral injection of orexin A. Peptides 29: 120-126.

21. Pellegrino LJ, Cushman AJ (1967) A stereotaxic atlas of the rat brain. AppletonCentury-Crofts, New York.

22. Monda M, Viggiano A, De Luca V (2003) Haloperidol reduces the sympathetic and thermogenic activation induced by orexin A. Neurosci Res 45: 17-23.

23. Fujiki N, Yoshida Y, Ripley B, Honda K, Mignot E, et al. (2001) Changes in CSF hypocretin-1 (orexin A) levels in rats across 24 hours and in response to food deprivation. Neuroreport 12: 993-997.

24. Tchernichovski O,Benjamini Y, Golani I (1998) The dynamics of long-term exploration in the rat. Part I. A phase-plane analysis of the relationship between location and velocity. Biol Cybern 78: 423-432.

25. Eilam D, Golani I (1989) Home base behavior of rats (Rattusnorvegicus) exploring a novel environment. Behav Brain Res 34: 199-211.

26. Hagan JJ, Leslie RA, Patel S, Evans ML, Wattam TA, et al. (1999) Orexin A activates locus coeruleus cell firing and increases arousal in the rat. Proc Natl Acad Sci USA 96: 10911-10916.

27. Mochizuki T, Crocker A, McCormack S, Yanagisawa M, Sakurai T, et al. (2004) Behavioral state instability in orexin knock-out mice. J Neurosci 24: 6291-6300.

28. Mochizuki T, Klerman EB, Sakurai T, Scammell TE (2006) Elevated body temperature during sleep in orexin knockout mice. Am J Physiol Regul Integr Comp Physiol 291: R533-540. 
Citation: Viggiano E, Messina G, Viggiano A, Viggiano A, Luca VD, et al. (2014) Effects of Orexin A on Thermal Behaviour: Substantial Evidences for Thermoregulatory Role of Orexin A. J Bioanal Biomed 6: 040-044. doi:10.4172/1948-593X.1000108

29. Ray B, Mallick HN, Kumar VM (2004) Changes in thermal preference, sleepwakefulness, body temperature and locomotor activity of rats during continuous recording for 24 hours. Behav Brain Res 154: 519-526.

30. Ray B, Mallick HN, Kumar VM (2005) Changes in sleep-wakefulness in the medial preoptic area lesioned rats: role of thermal preference. Behav Brain Res 158: 43-52.

31. Kumar D, Mallick HN, Kumar VM (2009) Ambient temperature that induces maximum sleep in rats. Physiol Behav 98: 186-191.

32. Ray B, Mallick H, Kumar VM (2001) Role of the medial preoptic area in thermal preference of rats. Indian J Physiol Pharmacol 45: 445-450.

33. Poole S, Stephenson JD (1977) Body temperature regulation and thermoneutrality in rats. Q J Exp Physiol Cogn Med Sci 62: 143-149.

34. Gordon CJ, Becker P, Ali JS (1998) Behavioral thermoregulatory responses of single- and group-housed mice. Physiol Behav 65: 255-262.

35. Mochizuki T,Klerman EB, Sakurai T, Scammell TE (2006) Elevated body temperature during sleep in orexin knockout mice. Am J Physiol Regul Integr Comp Physiol 291: R533-540.

36. Chemelli RM, Willie JT, Sinton CM, Elmquist JK, Scammell T, et al. (1999) Narcolepsy in orexin knockout mice: molecular genetics of sleep regulation. Cell 98: 437-451.

37. España RA, McCormack SL, Mochizuki T, Scammell TE (2007) Running promotes wakefulness and increases cataplexy in orexin knockout mice. Sleep 30: $1417-1425$.

38. Cannon B,Nedergaard J (2004) Brown adipose tissue: function and physiological significance. Physiol Rev 84: 277-359.

39. van den Pol AN (1999) Hypothalamic hypocretin (orexin): robust innervation of the spinal cord. J Neurosci 19: 3171-3182.

40. Monda M, Viggiano A, Viggiano A, Viggiano E, De Luca V (2006) Risperidone potentiates the sympathetic and hyperthermic reactions induced by orexin $A$ in the rat. Physiol Res 55: 73-78.

41. Sakurai T, Amemiya A, Ishii M, Matsuzaki I, Chemelli RM, et al. (1998) Orexins and orexin receptors: a family of hypothalamic neuropeptides and $\mathrm{G}$ proteincoupled receptors that regulate feeding behavior. Cell 92: 573-585.

42. Yamanaka A, Sakurai T, Katsumoto T, Yanagisawa M, Goto K (1999) Chronic intracerebroventricular administration of orexin-A to rats increases food intake in daytime, but has no effect on body weight. Brain Res 849: 248-252.

43. Ida T, Nakahara K, Katayama T, Murakami N, Nakazato M (1999) Effect of lateral cerebroventricular injection of the appetite-stimulating neuropeptide, orexin and neuropeptide $\mathrm{Y}$, on the various behavioral activities of rats. Brain Res 821: 526-529.

44. Monda M, Viggiano A, De Luca V (2003) Paradoxical [correction of parodoxical] effect of orexin A: hypophagia induced by hyperthermia. Brain Res 961: 220228.

45. Shiraishi T, Oomura Y, Sasaki K, Wayner MJ (2000) Effects of leptin and orexin-A on food intake and feeding related hypothalamic neurons. Physiol Behav 71: 251-261

46. Wolf $\mathrm{G}$ (1998) Orexins: a newly discovered family of hypothalamic regulators of food intake. Nutr Rev 56: 172-173.

47. Székely M, Pétervári E, Pákai E, Hummel Z, Szelényi Z (2005) Acute, subacute and chronic effects of central neuropeptide $Y$ on energy balance in rats. Neuropeptides 39: 103-115

48. Bray GA (1991) Obesity, a disorder of nutrient partitioning: the MONA LISA hypothesis. J Nutr 121: 1146-1162.
49. Nagase H, Bray GA, York DA (1996) Effect of galanin and enterostatin on sympathetic nerve activity to interscapular brown adipose tissue. Brain Res 709: 44-50.

50. Patel S, Hutson PH (1996) Effects of galanin on 8-OH-DPAT induced decrease in body temperature and brain 5-hydroxytryptamine metabolism in the mouse. Eur J Pharmacol 317: 197-204

51. Monda M, Viggiano A, Viggiano A, Fuccio F, De Luca V (2004) Clozapine blocks sympathetic and thermogenic reactions induced by orexinA in rat. Physiol Res 53: 507-513.

52. Monda M, Messina G, Vicidomini C, Viggiano A, Mangoni C, et al. (2006) Activity of autonomic nervous system is related to body weight in pre-menopausal, but not in post-menopausal women. Nutr Neurosci 9: 141-145.

53. Okamoto S, Kimura K, Saito M (2001) Anorectic effect of leptin is mediated by hypothalamic corticotropin-releasing hormone, but not by urocortin, in rats. Neurosci Lett 307: 179-182.

54. Messina G, Viggiano A, De Luca V, Messina A, Chieffi S, et al. (2013) Hormona changes in menopause and orexin-a action. Obstet Gynecol Int 2013: 209812.

55. Ukropec J,Seböková E, Klimes I (2001) Nutrient sensing, leptin and insulin action. Arch Physiol Biochem 109: 38-51.

56. Haque MS, Minokoshi Y, Hamai M, Iwai M, Horiuchi M, et al. (1999) Role of the sympathetic nervous system and insulin in enhancing glucose uptake in peripheral tissues after intrahypothalamic injection of leptin in rats. Diabetes 48. $1706-1712$

57. Haynes WG, Morgan DA, Djalali A, Sivitz WI, Mark AL (1999) Interactions between the melanocortin system and leptin in control of sympathetic nerve traffic. Hypertension 33: 542-547.

58. Tentolouris N, Liatis S, Katsilambros N (2006) Sympathetic system activity in obesity and metabolic syndrome. Ann N Y Acad Sci 1083: 129-152.

59. Monda M, Messina G, Mangoni C, De Luca B (2008) Resting energy expenditure and fat-free mass do not decline during aging in severely obese women. Clin Nutr 27: 657-659.

60. Messina G, Vicidomini C, Viggiano A, Tafuri D, Cozza V, et al. (2012) Enhanced parasympathetic activity of sportive women is paradoxically associated to enhanced resting energy expenditure. Autonomic Neuroscience: Basic and Clinical 169: 102-106.

61. Messina G, De Luca V, Viggiano A, Ascione A, lannaccone T, et al. (2013) Autonomic nervous system in the control of energy balance and body weight: personal contributions. Neurol Res Int 2013: 639280.

62. De Luca B, Monda M, Pellicano MP, Zenga A (1987) Cortical control of thermogenesis induced by lateral hypothalamic lesion and overeating. Am J Physiol 253: R626-633. 